it must have ever-recurring readjustment as its key note. Would that those who are busy making blue-prints of a better world would realize this ; so many of their schemes are static! Perhaps a main contribution of the humanist at the present juncture is the thought that man is a social being, and that, within society, there is an unceasing and not always successful struggle towards freedom of conscience, towards replacement of external by internal factors. One may add that the survivalvalue of this freedom is related to the facts of observation and inference, namely that life's history on earth has been a process of ever-recurring readjustments, and that, with few exceptions, the fate of those forms which did not readjust has been extinction. At the same time, it should be remembered that these developmental adjustments are selective ; if some features are enhanced, others are atrophied. So it is not very wise to suggest that the later include the earlier; that unduly simplifies the idea of change and suggests acceptance of the rather crude notion of the inevitability of progress.

\section{University of Manchester.}

\section{H. J. Fleure.}

OUT of the breakdown of traditional systems of thought, glimmers of new light appear, islands of solid land emerge out of the chaotic flood. Dropping metaphor, the question is whether any new system of thought, sufficiently strong to provide the foundation for living, can be evolved in time to substitute reintegration for disintegration. As science has played a major part in bringing about the disintegration of the old, it should attempt to do at least as much in the new integration.

Dr. Waddington's interesting article is a valuable contribution to this. As he points out, psychology, anthropology and sociology have largely contributed to the breakdown of traditional views on ethics. He might have added many other sciences. Evolutionary biology is one, with all its implications as to human ancestry, the struggle for existence, and the abolition of the idea of purpose in evolution. All the physical sciences have contributed, by providing a mechanistic explanation of natural phenomena previously attributed to supernatural powers and often invested with an ethical aura-witness the legend of the rainbow in the Old Testament, or the frequent view of lightning, floods or earthquakes as expressions of Divine anger. Similarly, physiology and pathology have removed deformity and infectious disease from the ethical sphere; they are no longer considered as Divine retribution for moral lapses.

When it comes to the constructive side, I have little to add to Dr. Waddington's interesting thesis.
He might, I think, have pointed out that in some cases science indicates a new ethic, or at least a new type of ethical approach to old problems. This may be illustrated by my last example. We can no longer believe that pestilence has any connexion with moral lapses in the conventional sense, or with the failure to observe certain rituals or to believe certain dogmas ; but we can lay down certain new types of moral duty arising out of the nature of infection-duties both individual and social, concerning cleanliness and the prevention of disease and of its spread.

I have two specific comments. One concerns the basis for the quality of absoluteness and otherworldliness possessed by the super-ego and the systems of ethics for which it is the vehicle. Dr. Waddington makes what I believe to be the quite novel suggestion that this is connected with the breakdown of the solipsistic early phase of the child's existence. While this may be a contributory cause of the other-worldliness, I cannot feel that it accounts for the absoluteness, for the fact that certain aspects of morality are felt as a categorical imperative. The origin of this, as I have elsewhere suggested, must more probably be sought in the all-or-nothing method adopted in higher animals for avoiding conflict. This has been proved to operate to prevent conflict between antagonistic muscles and between competing reflexes. Observation shows that it must also normally apply to competing instincts in subhuman vertebrates. Finally, all we know of human psychology indicates the strong probability that it operates in repression in early life. Man is the only organism in which conflict is normal and habitual, so that some form for minimizing its effects is essential ; and this will be of the greatest importance in early childhood, before sufficient experience has been accumulated to enable conflict to be dealt with empirically and rationally.

The antagonistic forces which hold down repressed ideas and impulses are kept away from the main body of consciousness; hence the apparent externality of ethical law. They are held there by the strong but automatic processes of repression; hence the compulsiveness of the super-ego. And repression is, or attempts to be, total, seeking to keep certain impulses wholly out of consciousness ; hence the all-or-nothing character of the ethical prohibitions of the super-ego.

Some repressions are more complete than others : and in many cases the degree and method of repression can be modified or the prohibitions of the super-ego transferred in their operations from one field to another. Hence we may say that a great part of our ethical development will consist in diminishing the absoluteness and compulsive- 
ness of our early categorical imperatives, and in altering the field to which they apply, in the light of reason and experience.

Put in another way, we may say that primitive and absolutist ethics, based on the non-rational and unconscious processes of the mind, inevitably tend to limit human activity by locking up conflicting psychological 'energies' in the repressive mechanism of the unconscious. For constructive and truly humanistic ethics, we need to liberate these forces from their unconscious grappling, through reason and still more by appropriate education and by opportunities for fuller living.

The other point which I would like to make is perhaps even more fundamental. Dr. Waddington writes: "an existence which is essentially evolutionary is itself the justification for an evolution towards a more comprehensive existence". While this is true, it is so general as to smack of Panglossic optimism. It is an observed fact that the majority of evolutionary trends are either irrelevant to progressive change, or are even opposed to it in direction, or are inherently limited specializations. As I have set out at some length elsewhere (in the first essay in my book "The Uniqueness of Man") evolutionary progress can be objectively defined, and further is a rare phenomenon ; the potentialities of further true progress now appear to be restricted to our own species, though there is no guarantee that we shall achieve them. The problem here is thus to study the possible directions of change; to decide which make for progress and which do not ; which make for unlimited and which for limited progress; and to attempt to adjust our social systems and our ethical ideas in such a way that, as Dr. Waddington rightly points out is possible, they should form a mutually reinforcing whole, making for the maximum speed of progress in the correct direction.

Dr. Waddington points out the difficulties arising from the fact that the ethical systems of different societies differ enormously, one conception of the good often contradicting another. Here again there is an evolutionary parallel. Thanks to the work of Sewall Wright, we know that small and isolated animal and plant species will often show 'accidental' differentiation, which is not necessarily biologically advanta eous, and may sometimes even be disadvantageous. The same appears to apply to the evolution of cultures.

Further, as Darlington has pointed out in his recent book, "The Evolution of Genetic Systems", certain evolutionary changes may be of immediate advantage, but of eventual disadvantage in robbing the stock of evolutionary plasticity and adaptability. Here again there are doubtless parallels from ethics. The short-term efficiency of ruthless State dictatorship as opposed to the inevitable long-term triumph of more humanistic systems is a case in point.

With such modifications, Dr. Waddington's thesis of ethical systems as indispensable social organs, derived from the impact of a changing external world on the minds of individuals via the social environment, but themselves then helping to effect changes in the external world and the social environment, appears to be a fundamental one, and worthy of the most careful study. Julian S. HuXley.

Zoological Society of London.

\section{SCIENCE AND MARXIST PHILOSOPHY}

$\mathrm{I}_{\mathrm{I}}^{\mathrm{T}}$ $\mathrm{T}$ is a little more than ten years since the London Congress on the History of Science. It was there that the Soviet delegation first brought effectively to the notice of British men of science the contributions that Marxist thought had to make to the natural and social sciences. The symposium organized by Marx House held during August 16-17 has served to show that there is now a widespread and growing interest in this development, and that we are clearly on the way towards a more profound and comprehensive appreciation of science as a human social activity. The two days sessions of the symposium had as keynotes two of Engels' works, "The Dialectics of Nature" and "The Origin of the Family", illustrative of the scientific and sociological aspects of his work.

The first was introduced by Prof. H. Levy, who discussed the changes that the present century has brought about in the attitudes towards philosophy and science, contrasting the older tendencies towards pure science cultivated for its own sake with those of a planned science in the service of the community. He showed how the former tendency is working itself out in the direction of the claims of a priori knowledge, as evidenced in the recent discussion in NATURE between Jeans and Eddington. The majority of men of science, however, are coming more and more to see their activity as part of social enterprise, and to realize that science represents the achievement of human action in an infinite field of ignorance; indeed, that in a sense, the man of science creates new ignorance with every problem he solves. The old absolute views of knowledge and logic are giving way to one in which probability has a much greater part. We need for the advancement of 